Journal of

Women's Health and Gynecology

\title{
Stress Urinary Incontinence Surgery with Mini Sling Just-Swing $₫$ System: Our Office Experience
}

\section{Ana Ribeiro*, Maria Boia, Ana Cláudia Santos, Isabel Ferreira, Filomena Ramos}

Department of Obstetrics and Gynecology, Centro Hospitalar do Baixo Vouga

${ }^{\star}$ Corresponding author: Ana Ribeiro, Obstetrics and Gynecology Department Centro Hospitalar Baixo Vouga, Portugal, Tel: +351-911-992-285, E-mail: anaribeiro0588@gmail.com

Received Date: February 25, 2019; Accepted Date: March 17, 2019; Published Date: March 19, 2019

Citation: Ana Ribeiro (2019) Stress Urinary Incontinence Surgery with Mini Sling Just-Swing® System: Our Office Experience. J Womens Health Gyn 5: 1-5.

\begin{abstract}
Objective: To evaluate the efficacy, short-term and long-term complications and satisfaction of our office experience with Just-Swing ${ }^{\circledR}$ system for the treatment of female IU.

Materials and Methods: We performed a prospective study of surgery with Just-Swing® system. From January 2016 to December 2017, 60 women with UI underwent Just-Swing®system surgery.

Results: $96 \%(n=58)$ of patients showed objective cure (56,3\% with MUI and 43,7\% with SUI) at 2 months and 1 -year follow-up. No major complications occur. The satisfaction rate was $96 \%$ and most patients were very satisfied with the end result of the surgery.
\end{abstract}

Conclusions: The Just-Swing ${ }^{\circledR}$ system is a safe and highly effective method for SUI and it can be performed successfully under local anesthesia in an ambulatory setup.

Keywords: Urinary incontinence; Stress; anesthesia, Local; mini-sling; Office experience 


\section{Introduction}

Stress urinary incontinence (SUI) is the most common type of female urinary incontinence (UI). In Portugal, SUI affects about $30 \%$ of women over 40 years of age. Surgery plays a preponderant role in SUI treatment $[1,14]$.

Surgical treatment of SUI has evolved in recent decades towards minimally invasive approaches. After Ulmesten et al. publication on the retropubic urethral sling without tension (TVT) the mid-urethral slings (retropubic, trans-obturator and single incision sling or mini-slings) have become the most common surgical procedures for female SUI correction $[3,4]$.

The single incision sling or mini-sling is associated with lesser potential complications and it also allows the intervention to be performed under local anesthesia. This fact allowed its office implementation, which has been practiced in our Hospital since 2013.

\section{Objective}

The aim of this publication is to evaluate the efficacy, short-term and long-term complications and satisfaction of our office experience with Just-Swing ${ }^{\circledR}$ system for the treatment of female IU.

\section{Materials and Methods}

The Just-Swing ${ }^{\circledR}$ mini-sling is used for surgical treatment of female stress urinary incontinence. The sling is positioned beneath the urethra and anchored to the obturator foramen. The $3 \mathrm{~cm}$ mini-sling is made of polypropylene monofilament. Assembled with two titanium mini-anchors on a thread with a sliding knot and a knot pusher to adjust sling tension on both (Figure. 1, 2).
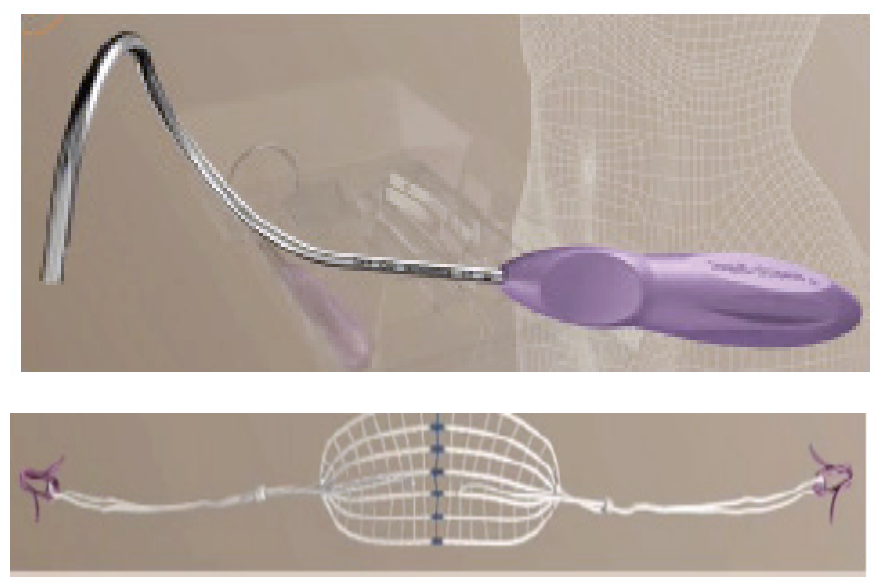

(Figure. 1 and 2) - image of the Just-Swing ${ }^{\oplus}$ mini-sling system
We performed a prospective study of surgery with Just-Swing®system. From January 2016 to December 2017, 60 women with UI underwent Just-Swing ${ }^{\circledR}$ system surgery. $55 \%(n=33)$ of the patients suffered from mixed urinary incontinence (MUI) and 45\% ( $\mathrm{n}=27)$ from SUI (Figure. 2). The average age was 53 years-old (Figure 3$) .13 \%(n=8)$ of the women had previous gynecological surgery (Figure. 4) [2].

We analyzed data on the clinical and urodynamic characteristics of the patients, intra and postoperative complications (early and late), and short-term (2 months) and long-term follow-up (1 year after surgery). During follow-up, the patient's clinical history, the degree of satisfaction after the surgery, and the physical examination with a stress test were evaluated. Cure was objectified with negative stress test with full bladder. All these procedures were performed with local anesthesia (Marcaine), with previous administration of antibiotic therapy (clindamycin 900ev) and in an "outpatient surgery", with evaluation of the pain scale [5,7-10].

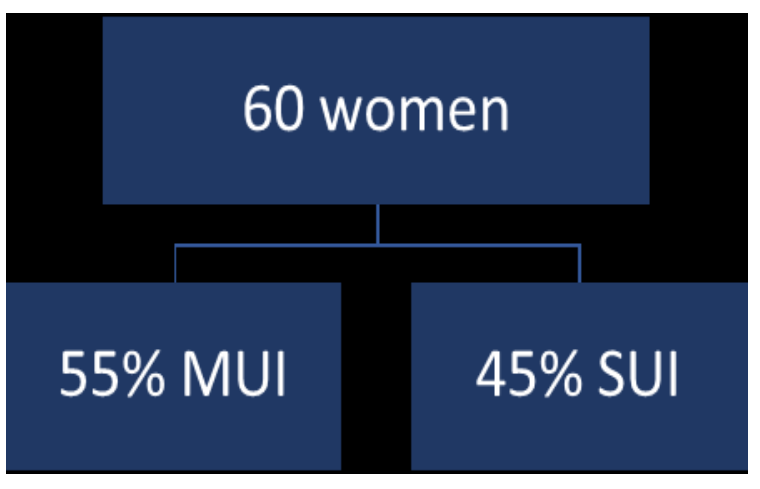

(Figure. 2)

\begin{tabular}{|lc|}
\hline \multicolumn{1}{|c|}{ Age } & (years) \\
\hline Minimum & 35 \\
\hline Maximum & 80 \\
\hline Average & 53 \\
\hline
\end{tabular}

(Figure. 3) 


\begin{tabular}{|lc|}
\hline \multicolumn{2}{|c|}{ Previous Gynecological Surgery } \\
\hline Abdominal total hysterectomy & 5 \\
\hline Vaginal hysterectomy & 1 \\
\hline Anterior colpoplasty & 1 \\
\hline $\begin{array}{l}\text { Previous urinary incontinence corrective } \\
\text { surgery - MiniArc }\end{array}$ & 1 \\
\hline
\end{tabular}

(Figure. 4)

\section{Results}

Evaluating the success rates of anti-incontinence surgery, $96 \%(n=58)$ of patients showed objective cure $(56,3 \%$ with MUI and 43,7\% with SUI) at 2 months and 1-year followup. One patient had only improvement but not cure with surgical correction. Surgical failure occurred in 1 case due to tape exposure ant the patient was reintervened trough Burch's surgery. The Surgical Success Rate (cure + improvement) was 98\% (Figure. 5). The pain targeted by patients during surgery was on average 2 (minimum 1 and maximum 6 ) on a scale of 0 to 10 (Figure. 6). There were no intraoperative complications. The early postoperative complications were: 1 case of pain on the inner side of the thigh and 3 cases of cystitis. As late postoperative complications included 1 case of tape exposure in vagina, already described, and 3 cases of unilateral inguinal pain that resolved spontaneously or oral analgesics (Figure. 7). There was also 1 case of worsening urgency incontinence symptoms in a woman with MUI 1 year after surgery, that required treatment with anticholinergics (Figure. 8). The satisfaction rate was $96 \%$ and most patients were very satisfied with the end result of the surgery (Figure. 9).

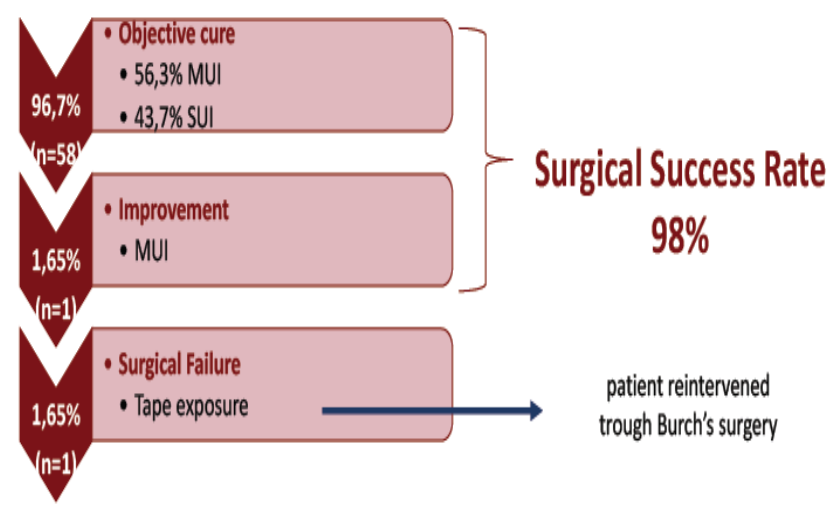

(Figure. 5)

\begin{tabular}{|lc|}
\hline Pain Scale & $(0-10)$ \\
\hline Minimum & 1 \\
\hline Maximum & 6 \\
\hline Average & 2 \\
\hline
\end{tabular}

(Figure. 6)

\begin{tabular}{|c|c|c|c|c|c|}
\hline \multicolumn{5}{|c|}{ Complications } & \\
\hline Intraoperative & \multicolumn{2}{|c|}{ Early Postoperative } & \multicolumn{2}{|c|}{ Later postoperative } & \\
\hline \multirow{3}{*}{0} & - Cystitis & 3 & - Tape exposure & 1 & \\
\hline & - Pain on the inner & & - Unilateral inguinal & & \multirow{3}{*}{$\begin{array}{c}\text { resolved spontaneously } \\
\text { of } \\
\text { oral analgesics }\end{array}$} \\
\hline & side of the thigh & 1 & pain & 3 & \\
\hline $0 \%$ & \multicolumn{2}{|l|}{$5 \%$} & \multicolumn{2}{|l|}{$5 \%$} & \\
\hline
\end{tabular}

(Figure. 7)

\section{MIU - Urgency Incontinence Symptoms}

\begin{tabular}{|l|c|c|}
\hline & $1 \mathrm{M}$ & $12 \mathrm{M}$ \\
\hline Stabilization & 31 & 30 \\
\hline Improvement & 2 & 2 \\
\hline Worsening & 0 & 1 \\
\hline
\end{tabular}

(Figure. 8)

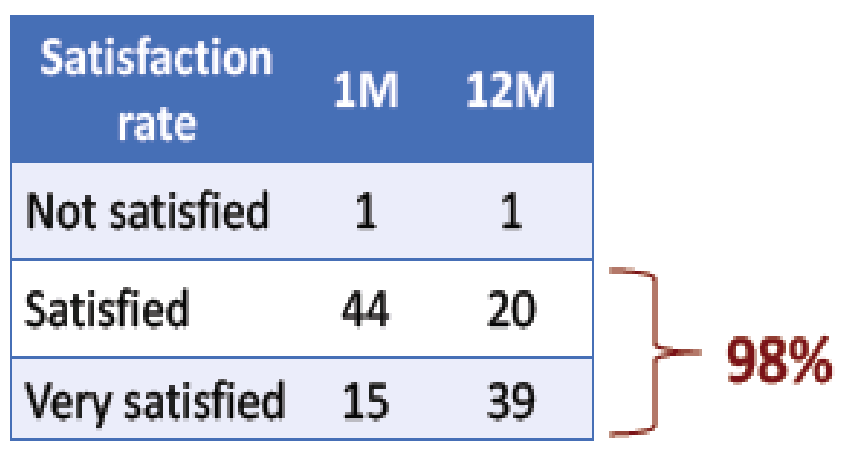




\section{Conclusions}

The mini-sling Just-Swing ${ }^{\circledR}$ system is an excellent anti-incontinence procedure. Both sides of the mini-sling are adjustable which permits precise adjustment of sling tension. It has an innovative system with fixation to the obturator membrane, avoiding external incisions [9-13].

Its greatest advantage lies in the possibility of performing the surgery under local anesthesia, allowing the patient to do the stress test and to test and adjust the sling's tension according to the woman's needs. It is important to point out that the surgery was performed in almost all cases, with minimal discomfort, which reinforces the possibility of its accomplishment in an "outpatient surgery". Performing the stress test during the procedure contributes to the high success rate. Simplified system tuning allows minimizing trauma, bleeding, and thus achieving a low number of complications. The results presented in our series are in agreement with the literature. However, the findings of this study should be further confirmed by well-designed prospective studies with a larger patient series.

\section{References}

1. Minassian VA, Stewart WF, Wood GC. (2008) Urinary incontinence in women: variation in prevalence estimates and risk factors. Obstet Gynecol. 111:324-31.

2. Kennelly MJ, Moore R, Nguyen JN, Lukban JC, Siegel S. (2010) Prospective evaluation of a single incision sling for stress urinary incontinence. J Urol. 184:604-9.

3. Ulmsten U, Petros P. (1995) Intravaginal slingplasty (IVS): an ambulatory surgical procedure for treatment of female urinary incontinence. Scand J Urol Nephrol. 29:75-82.

4. Cox A, Herschorn S, Lee L. (2013) Surgical management of female SUI: is there a gold standard? Nat Rev Urol. 2013;10:78-89. Erratum in: Nat Rev Urol. 10:188.

5. Deng DY, Rutman M, Raz S, Rodriguez LV. (2007) Presentation and management of major complications of mid urethral slings: Are complications under-reported? Neurourol Urodyn. 26:46-52.

6. Abdel-Fattah M, Ford JA, Lim CP, Madhuvrata P. (2011) Single- incision mini-slings versus standard midurethral slings in surgical management of female stress urinary incontinence: a meta-analysis of effectiveness and complications. Eur Urol. 60:468-80.

7. Presthus JB, Van Drie D, Graham C. (2012) MiniArc single- incision sling in the office setting. J Minim Invasive Gynecol. 19:331-8.

8. Wang YJ, Li FP, Wang Q, Yang S, Cai XG, Chen YH. (2011) Comparison of three mid-urethral tension-free tapes (TVT, TVT-O, and TVT-Secur) in the treatment of female stress urinary incontinence: 1-year follow-up. Int Urogynecol J. 22:1369-74.

9. Moore RD, Mitchell GK, Miklos JR. (2009) Single-center retrospective study of the technique, safety, and 12-month efficacy of the MiniArcTM single-incision sling: a new minimally invasive procedure for treatment of female SUI. Surg Technol Int.18:175-81.

10. Natale F, Dati S, La Penna C, Rombolà P, Cappello S, Piccione E. (2014) Single incision sling (AjustTM) for the treatment of female stress urinary incontinence: 2-year followup. Eur J Obstet Gynecol Reprod Biol. 182:48-52.

11. Schellart RP, Oude Rengerink K, Van der Aa F, Lucot JP, Kimpe B, de Ridder DJ, et al. (2014) A randomized comparison of a single-incision mid urethral sling and a trans obturator midurethral sling in women with stress urinary incontinence: results of 12-mo follow-up. Eur Urol. 66:1179-85.

12. Angleitner-Flotzinger J, Aigmueller T. (2014) Mid- 
term follow-up of the TVT-Secur midurethral sling for primary stress incontinence. Eur J Obstet Gynecol Reprod Biol. 180:24-7.

13. Mostafa A, Lim CP, Hopper L, Madhuvrata P, AbdelFattah M. (2014) Single-incision mini-slings versus standard midurethral slings in surgical management of female stress urinary incontinence: an updated systematic review and metaanalysis of effectiveness and complications. Eur Urol. 65:40227.

14. Hunskaar S, Lose G, Sykes D, Voss S. (2004) The prevalence of urinary incontinence in women in four European countries. BJU Int. 93:324-30.

\section{Submit your manuscript to a JScholar journal} and benefit from:

ๆ Convenient online submission

ฯ Rigorous peer review

ף Immediate publication on acceptance

ๆ Open access: articles freely available online

9 High visibility within the field

ब Better discount for your subsequent articles Submit your manuscript at http://www.jscholaronline.org/submit-manuscript.php 